\title{
Determination of factors controlling the particle size and entrapment efficiency of noscapine in PEG/PLA nanoparticles using artificial neural networks
}

\author{
This article was published in the following Dove Press journal: \\ International Journal of Nanomedicine \\ 23 October 2014 \\ Number of times this article has been viewed
}

\section{Karim S Shalaby' \\ Mahmoud E Soliman' \\ Luca Casettari² \\ Giulia Bonacucina ${ }^{3}$ \\ Marco Cespi ${ }^{3}$ \\ Giovanni F Palmieri ${ }^{3}$ \\ Omaima A Sammour ${ }^{1}$ \\ Abdelhameed A El Shamy ${ }^{1, \dagger}$ \\ 'Department of Pharmaceutics and Industrial Pharmacy, Faculty of Pharmacy, Ain Shams University, Cairo, Egypt; ' 2 Department of Biomolecular Sciences, School of Pharmacy, University of Urbino, Urbino, Italy; ${ }^{3}$ School of Pharmacy, University of Camerino, Camerino, Italy}

${ }^{\dagger}$ Abdel Hameed El-Shamy passed away on August 25, 2013
Correspondence: Mahmoud E Soliman Boots Science Building, School of Pharmacy, University of Nottingham, University Park, Nottingham NG7 2RD, UK

Emailmahmoud.e.soliman@pharma.asu. edu.eg
Abstract: In this study, di- and triblock copolymers based on polyethylene glycol and polylactide were synthesized by ring-opening polymerization and characterized by proton nuclear magnetic resonance and gel permeation chromatography. Nanoparticles containing noscapine were prepared from these biodegradable and biocompatible copolymers using the nanoprecipitation method. The prepared nanoparticles were characterized for size and drug entrapment efficiency, and their morphology and size were checked by transmission electron microscopy imaging. Artificial neural networks were constructed and tested for their ability to predict particle size and entrapment efficiency of noscapine within the formed nanoparticles using different factors utilized in the preparation step, namely polymer molecular weight, ratio of polymer to drug, and number of blocks that make up the polymer. Using these networks, it was found that the polymer molecular weight has the greatest effect on particle size. On the other hand, polymer to drug ratio was found to be the most influential factor on drug entrapment efficiency. This study demonstrated the ability of artificial neural networks to predict not only the particle size of the formed nanoparticles but also the drug entrapment efficiency. This may have a great impact on the design of polyethylene glycol and polylactide-based copolymers, and can be used to customize the required target formulations.

Keywords: noscapine, polyethylene glycol (PEG), polylactide (PLA), biodegradable nanoparticles, artificial neural networks (ANNs)

\section{Introduction}

Biopolymer-based nanoparticles (NPs) have been extensively studied as delivery systems for different therapeutics. Polymeric micelle-like particles, composed of a hydrophilic part and a hydrophobic part, hold promise as nanocarriers for drug delivery, due to their ability to incorporate hydrophobic drugs inside their hydrophobic core (Figure 1)

As a drug delivery system, they have the advantage of being of small size (10-200 nm), which allows a long circulation time and reduces opsonization and detection by macrophages. ${ }^{1,2}$ This will lead to their high stability and sustained drug release. Moreover, their small size and long circulation time favor their passive accumulation within tumor cells. ${ }^{1}$ They are less likely to cause hypersensitivity than stealth liposomes while achieving greater penetration of solid tumors. ${ }^{2}$ Polymeric NPs composed of polyethylene glycol (PEG) and polylactide (PLA) in di- and triblock copolymers have been used as delivery systems for chemotherapeutic drugs with high entrapment efficiency and small particle size. Currently, some of those systems are in various phases of clinical trials. ${ }^{1,3,4}$ 


\section{A}
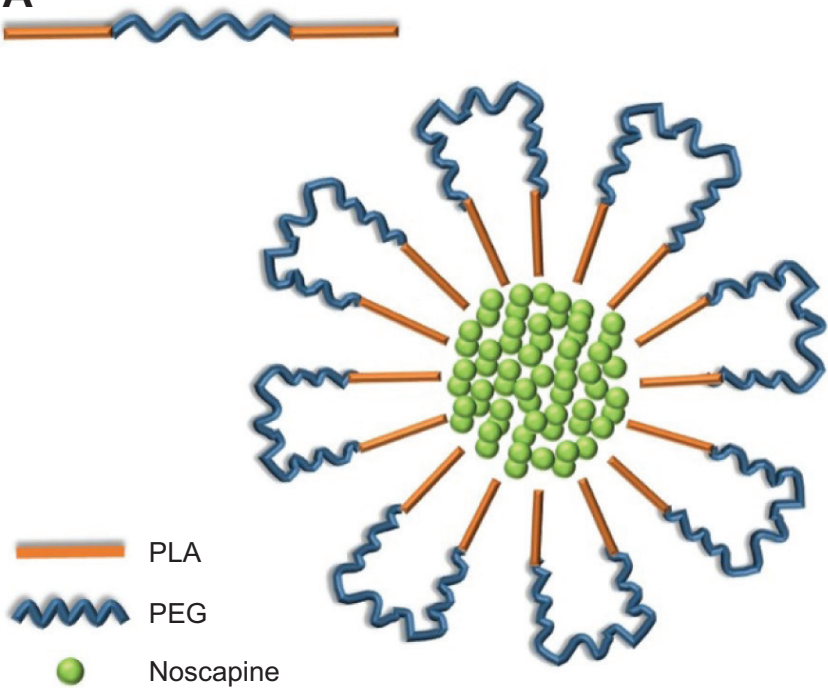

B
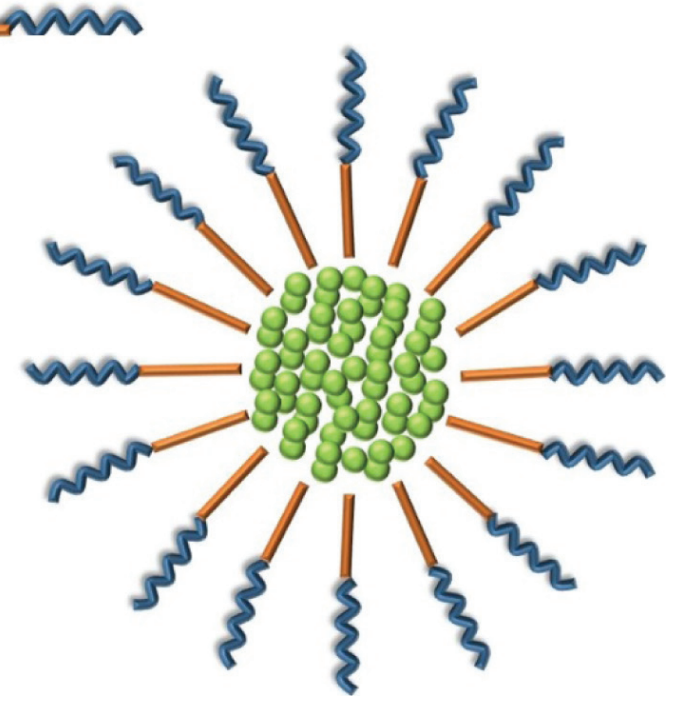

Figure I Di- and triblock copolymers and their association to form nanoparticles that can contain noscapine.

Notes: (A) Polymeric nanoparticles of triblock PLA-PEG-PLA. (B) Polymeric nanoparticles of diblock PEG-PLA.

Abbreviations: PEG, polyethylene glycol; PLA, polylactide.

Noscapine, an alkaloid derived from opium, has been widely used as an antitussive agent. ${ }^{5-7}$ Recently, it was discovered to have a tubulin-binding activity. It affects the dynamics of microtubules, arresting the metaphase of the cell cycle, and, by doing so, eventually leads to apoptosis of dividing cancer cells. ${ }^{8-18}$

Due to its limited toxicity, it has been used for the treatment of different types of solid tumor, such as prostate, lung, brain, and breast cancer. ${ }^{9,19-21}$ However, it was also found to have a limited cytotoxic effect, which could be attributed to its inability to be concentrated within cancer cells.

Artificial neural networks (ANNs) are computer programs that simulate the neurons in the human brain and the way it processes data. They are composed of connecting neurons between inputs and outputs. In between the neurons, there are nodes that mimic the synapses between biological neurons (Figure 2). The number of connecting neurons in a specific network determines the power of neural computations. Each neuron in ANNs delivers the data to the following neuron through a transfer function, and after the data are processed through the designed number of neurons, the network produces its output. This output is then compared with the actual output, and then the difference between the actual and predicted data is calculated as an error. This error aids in the process by which the network learns through a predetermined learning rule, by adjusting the weights of the connecting neurons and then reprocessing the data. This learning process of the network in the form of iterations, which is called "network training", is continued until the lowest values of error are obtained. ${ }^{22}$
ANNs are usually used to determine nonlinear relationships between inputs and outputs. The concept of ANNs has been used in different fields of pharmaceutical research since the 1990s. ${ }^{23,24}$ It has been used to model the methods used to analyze some drugs: eg, ranitidine and corynoxeine. ${ }^{25-27}$ It was also used to determine the physicochemical properties of amorphous polymers and the dissolution parameters of diltiazem in preformulation studies. ${ }^{28,29}$ It has also been used to identify the factors that affect the properties of nanoscale drug delivery systems such as nanoemulsions and polymeric NPs. ${ }^{30-32}$

The aim of this study was to prepare and characterize noscapine-containing polymeric NPs composed of di- and triblock copolymers of PLA/PEG and to use ANNs to determine the effect of polymer molecular weight, polymer to drug ratio, and the number of blocks within the polymer on the particle size and entrapment efficiency of the drug within the formed polymeric NPs.

\section{Materials and methods Materials}

Methoxy-PEG (mPEG) $1.9 \mathrm{kDa}$ and PEG $2 \mathrm{kDa}$ were purchased from Polysciences, Inc. (Warrington, PA, USA) and D,L-lactide was purchased from PURAC Biochem (Gorinchem, the Netherlands). Stannous-2-ethyl-hexanoate was purchased from Sigma-Aldrich Co. (St Louis, MO, USA). Noscapine was a gift sample from EIPICO (El Asher of Ramadan, Egypt). Chloroform, dichloromethane (DCM), and diethyl ether were all of analytical grade and used without any further manipulation. 


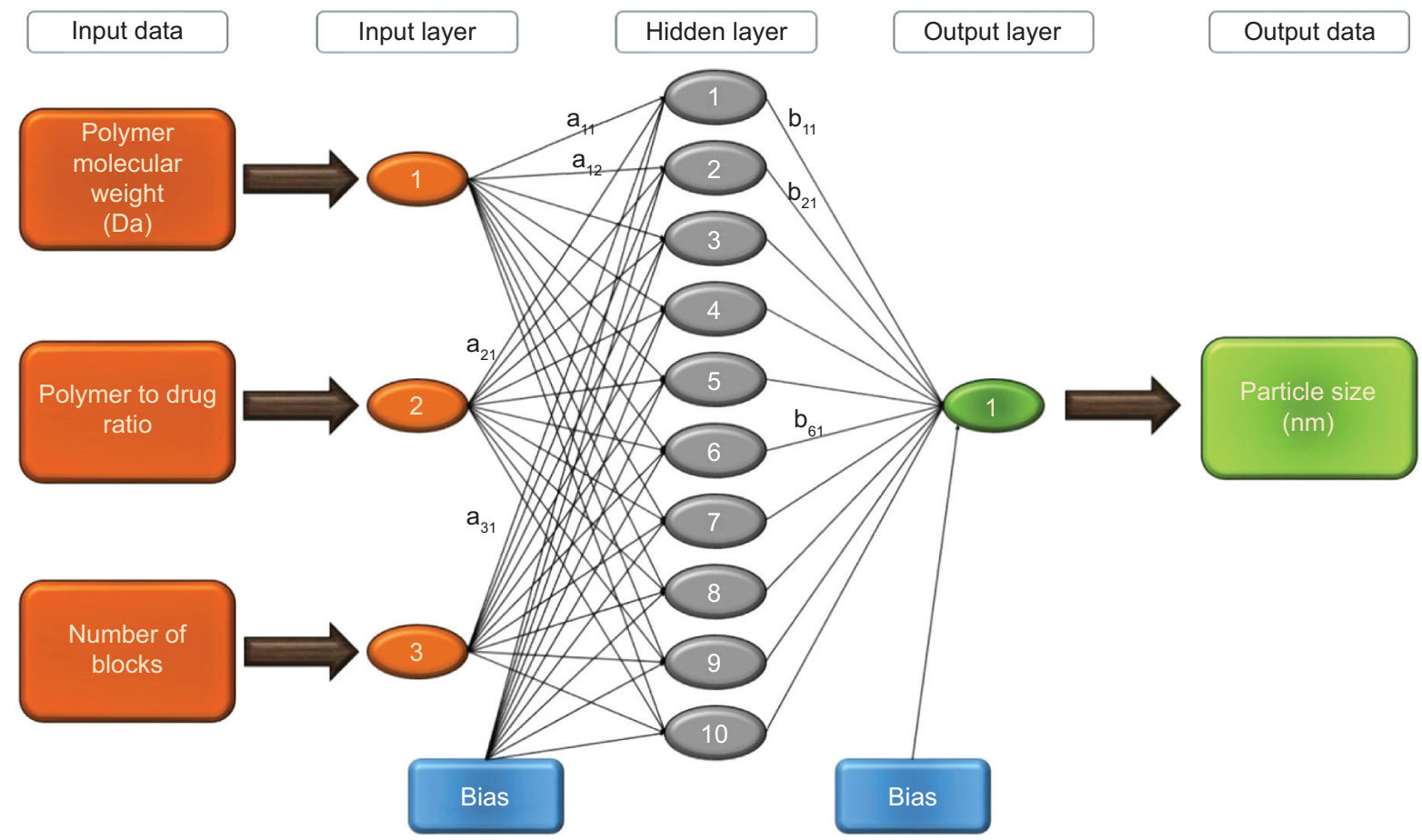

Figure 2 Architecture of the artificial neural network used to predict particle size.

\section{Methods}

\section{Synthesis of block copolymers}

Both di- and triblock copolymers were synthesized by the ring-opening polymerization method. ${ }^{33-35} \mathrm{mPEG} 1.9 \mathrm{kDa}$ or PEG $2 \mathrm{kDa}$ was added to a three-neck, round-bottom flask, melted at $150^{\circ} \mathrm{C}$ under nitrogen atmosphere, and magnetically stirred. Proper amounts of D,L-lactide were added to the flask, then polymerization was started by the addition of different amounts of the catalyst, stannous-2-ethylhexanoate, to the mixture, and the reaction was heated at $150^{\circ} \mathrm{C}$ for specified time intervals (Table 1). A small amount of DCM was added to the mixture to dissolve the polymers and decrease the mixture viscosity. The DCM solution was then added to cold diethyl ether, under stirring, to precipitate the copolymers. Polymers, in the form of white powder or pale yellow wax, were kept under vacuum and then stored at $2^{\circ} \mathrm{C}-8^{\circ} \mathrm{C}$ until further investigation.

\section{Characterization of block copolymers}

Proton nuclear magnetic resonance ('H NMR) spectroscopy

${ }^{1} \mathrm{H}$ NMR spectra were recorded on a Bruker AC $200 \mathrm{MHz}$ spectrometer. Samples were dissolved in $\mathrm{CDCl}_{3}$. Chemical shift values were reported in parts per million $(\delta)$ downfield from the internal standard tetramethylsilane $\left(\mathrm{Me}_{4} \mathrm{Si}\right)$.

\section{Gel permeation chromatography (GPC)}

Copolymer $7.5 \mathrm{mg}$ was solubilized in $1.5 \mathrm{~mL}$ of $\mathrm{CHCl}_{3}$ at $40^{\circ} \mathrm{C}$ for 1 hour. The solution was filtered through a $0.45 \mu \mathrm{m}$ pore size regenerated cellulose syringe filter, then $7.5 \mu \mathrm{L}$ of

Table I Composition and molecular weight of block copolymers used in the preparation of nanoparticles

\begin{tabular}{|c|c|c|c|c|c|c|c|c|c|}
\hline & \multirow[t]{2}{*}{ Polymer } & \multirow{2}{*}{$\begin{array}{l}\text { mPEG } \\
(\mathrm{g})\end{array}$} & \multirow{2}{*}{$\begin{array}{l}\text { Lactide } \\
\text { (g) }\end{array}$} & \multirow{2}{*}{$\begin{array}{l}\text { Time } \\
\text { (h) }\end{array}$} & \multirow{2}{*}{$\begin{array}{l}\text { Yield } \\
\text { (g) }\end{array}$} & \multirow{2}{*}{$\begin{array}{l}\text { Yield } \\
\%\end{array}$} & \multirow{2}{*}{$\begin{array}{l}\text { Mwt } \\
\text { (NMR) }\end{array}$} & \multicolumn{2}{|l|}{ GPC } \\
\hline & & & & & & & & Mn (Da) & PDI \\
\hline $\mathrm{PI}$ & $P(D, L) L A-P E G 2000 D a-P(D, L) L A$ & 4 & 5 & 6 & 7.2 & 80.00 & 4,000 & 4,672 & 1.376 \\
\hline P2 & $P(D, L) L A-P E G 2000 D a-P(D, L) L A$ & 4 & 8 & 18 & 9.4 & 78.33 & 6,000 & 6,673 & 1.6208 \\
\hline P3 & $P(D, L) L A-P E G 2000 D a-P(D, L) L A$ & 4 & 24 & 24 & 15 & 53.57 & 14,000 & 15,605 & 2.0179 \\
\hline P4 & mPEG 1.9 kDa-P(D,L)LA & 3 & 2 & 5 & 3.3 & 66.00 & 2,700 & 3,023 & 1.2416 \\
\hline P5 & mPEG I.9 kDa-P(D,L)LA & 3 & 4 & 8 & 4.7 & 67.14 & 4,300 & 4,366 & 1.9233 \\
\hline P6 & mPEG I.9 kDa-P(D,L)LA & 3 & 9 & 24 & 9.11 & 75.92 & 7,000 & 10,492 & 1.9939 \\
\hline P7 & mPEG I.9 kDa-P(D,L)LA & 2.7 & 2.7 & 6 & 3.8 & 70.37 & 3,700 & 3,511 & $1.598 \mid$ \\
\hline
\end{tabular}

Abbreviations: GPC, gel permeation chromatography; mPEG, methoxypolyethylene glycol; Mwt, molecular weight; NMR, nuclear magnetic resonance; PDI, polydispersity index; Mn, number-average molecular weight. 
di- $\mathrm{CH}_{3} \mathrm{CN}$ was added to the tested samples and used as a flow marker. The analyses were carried out using an HP high-performance liquid chromatography system equipped with a gel permeation column (G2500HHR from Tosoh Bioscience) at $35^{\circ} \mathrm{C}$ with tetrahydrofuran as eluent at a flow of $1 \mathrm{~mL} / \mathrm{min}$. A standard calibration curve was achieved using a Polyethylene Glycol Calibration Kit (PL2070-01000 by Varian) with molecular weight ranging from $106 \mathrm{Mp}$ to 21,300 Mp. Data were analyzed by Clarity software (DataApex).

\section{Preparation of NPs}

NPs were prepared according to the nanoprecipitation method specified by Fessi et al. ${ }^{36}$ Polymer and noscapine in different ratios $(20: 1,10: 1,5: 1$, and 2.5:1) were accurately weighed and dissolved in acetone $(1 \mathrm{~mL})$. The organic phase was added dropwise into deionized water $(10 \mathrm{~mL})$ and stirred magnetically at 1,000 rpm until complete evaporation of acetone. The NPs thus produced were centrifuged (cooling centrifuge, Z216, HERMLE Labortechnik, Wehingen, Germany) at 15,000 rpm for 30 minutes, then washed twice using deionized water and freeze dried (Laboratory Freeze Drier Alpha 1-4, Martin Christ Gefriertrocknungsanlagen $\mathrm{GmbH}$, Osterode am Harz, Germany).

\section{Characterization of the prepared NPs}

\section{Particle size and zeta potential determinations}

The average particle diameter (Z-average) and size distribution (polydispersity index) of the prepared NPs in deionized water were measured by dynamic light scattering, while the zeta potential was determined by electrophoretic light scattering using a Zetasizer Nano ZS (Malvern Zetasizer; Malvern Instruments Ltd., Malvern, UK) equipped with $4 \mathrm{~mW} 633 \mathrm{~nm}$ He-Ne lasers. Samples were properly diluted with deionized water and equilibrated at $25^{\circ} \mathrm{C}$, and analyses were typically performed at a fixed angle of $173^{\circ}$. The average particle diameter ( $Z$-average), the polydispersity index, and the average zeta potential values were obtained from the data of at least 12 runs. Data are shown as the mean value of at least three measurements.

\section{Determination of noscapine entrapment efficiency}

For the determination of noscapine entrapment efficiency, NPs were dissolved in a 1:9 mixture of chloroform and methanol, and noscapine concentration was determined at $291 \mathrm{~nm}$ using ultraviolet spectroscopy (Shimadzu, Tokyo, Japan).

\section{Transmission electron microscopy (TEM)}

Samples were prepared by adding $10 \mu \mathrm{L}$ of the NP suspension to copper grids. Samples were then dried by exposing the copper grids to dry filtered air for $\sim 5$ minutes, and subsequently TEM (Jeol 1010; JEOL Ltd., Tokyo, Japan) was used to image them in air with an accelerating voltage of $100 \mathrm{kV}$.

\section{Experimental design and ANN modeling Software}

The ANN analysis was developed using MATLAB R2013a software (version 8.1) in order to model the complex nonlinear relation between inputs and outputs and to preset the outputs as three-dimensional (3-D) graphs instead of the linear statistical models.

\section{Experimental design and data set}

Twenty-seven experiments were performed using acetone as a solvent for the polymer and the drug. The stirring rate was fixed at 1,000 rpm and the drug concentration was a constant $100 \mu \mathrm{g} / \mathrm{mL}$. The solvent ratio was kept at $1 \mathrm{~mL}$ organic phase to $10 \mathrm{~mL}$ aqueous phase. Three input variables, polymer molecular weight, number of blocks in the used copolymer, and ratio of polymer to drug, were considered for ANN training with the output to be either the size of the formed NPs or noscapine entrapment efficiency within the formed NPs.

To avoid overtraining during the network training, two strategies were used. The maximum number of iterations was set to 500 and the data records were divided into training set, validation set, and test set. The training set was used to train the network and adjust the weights of connecting neurons through back-propagation. The validation set was used to detect the generalization of the emerging network. The software uses this set of data to prevent overtraining of the network, as training terminates when the mean square error (MSE) (Equation 1) of the training and validation data reaches the minimum:

$$
\mathrm{MSE}=\frac{\sum_{i=1}^{n}\left(y_{i}-\hat{y}_{i}\right)^{2}}{n}
$$

where $y$ is the observed output, $\hat{y}$ is the predicted output value from the model, and $n$ is the number of data set. When the MSE of the validation data starts to increase, it shows that the network is becoming overtrained and training must be stopped. The test set of data, as its name indicates, was used to test the network independently from the training process to assure its applicability for general data. "Training data" were used to train the network created and to develop relationships between input variables and output data. Random data sets were used to assess the quality of the model and to prevent overtraining as "validation data", and additional data sets were used as "test data" to assess the ability to use the 
trained neural network in the prediction of the output from general data. Detailed descriptions of the input variables for the experiments performed are given in Table 2.

\section{Training, test, and validation}

Training of networks was performed using feed-forward back-propagation with hyperbolic tangent sigmoid function as a transfer function for hidden and output layers. Each network was trained at least three times using new random sets of initial weights, and in each cycle the maximum number of iterations was set to 500. The Levenberg-Marquardt learning method and its practical implementations in the Neural Network Toolbox in MATLAB were used as the learning function for the formed networks. In order to determine the architecture of the networks and to avoid overfitting, we started from the lowest number of neurons in the hidden layer up to the smallest number of neurons that generates a network with high prediction capability without the occurrence of

Table 2 Input variables for the experiments performed (training, validation, and test data sets)

\begin{tabular}{|c|c|c|c|}
\hline $\begin{array}{l}\text { Sample } \\
\text { number }\end{array}$ & $\begin{array}{l}\text { Polymer } \\
\text { molecular } \\
\text { weight (Da) }\end{array}$ & $\begin{array}{l}\text { Ratio of } \\
\text { polymer } \\
\text { to drug }\end{array}$ & $\begin{array}{l}\text { Number of } \\
\text { blocks in the } \\
\text { copolymer }\end{array}$ \\
\hline 1 & 2,700 & 20 & 2 \\
\hline 2 & 2,700 & 10 & 2 \\
\hline 3 & 2,700 & 5 & 2 \\
\hline 4 & 2,700 & 2.5 & 2 \\
\hline 5 & 4,000 & 20 & 3 \\
\hline 6 & 4,000 & 10 & 3 \\
\hline $7^{a}$ & 4,000 & 5 & 3 \\
\hline $8^{a}$ & 4,000 & 2.5 & 3 \\
\hline $9^{b}$ & 4,300 & 20 & 2 \\
\hline $10^{\mathrm{c}, \mathrm{d}}$ & 4,300 & 10 & 2 \\
\hline $\mathrm{II}^{\mathrm{a}}$ & 4,300 & 5 & 2 \\
\hline $12^{c}$ & 4,300 & 2.5 & 2 \\
\hline $13^{b, d}$ & 6,000 & 20 & 3 \\
\hline 14 & 6,000 & 10 & 3 \\
\hline 15 & 6,000 & 5 & 3 \\
\hline $16^{d}$ & 6,000 & 2.5 & 3 \\
\hline $17^{\mathrm{a}}$ & 7,000 & 20 & 2 \\
\hline 18 & 7,000 & 10 & 2 \\
\hline 19 & 7,000 & 5 & 2 \\
\hline $20^{c}$ & 7,000 & 2.5 & 2 \\
\hline 21 & 14,000 & 10 & 3 \\
\hline 22 & 14,000 & 5 & 3 \\
\hline 23 & 14,000 & 2.5 & 3 \\
\hline $24^{b}$ & 3,700 & 20 & 2 \\
\hline 25 & 3,700 & 10 & 2 \\
\hline 26 & 3,700 & 5 & 2 \\
\hline $27^{d}$ & 3,700 & 2.5 & 2 \\
\hline
\end{tabular}

Notes: ${ }^{a}$ and ${ }^{d}$ indicate the input data sets used as the "validation data" and "test data", respectively, in drug entrapment efficiency model; ${ }^{b}$ and "indicate the input data sets used as the "validation data" and "test data", respectively, in particle size model. The rest of the data in each model were used as a "training set". overfitting. This was done with the knowledge that by increasing network size, the error of the training data decreases, while the error of the test data increases. Hence, networks were formed by determining the optimum values of errors between test data and training data. The correlation coefficient $\left(R^{2}\right)$ (Equation 2) and MSE (Equation 1) for training, test, and validation data sets were used to determine the quality of training and the predictability of the models: ${ }^{30,37}$

$$
R^{2}=\frac{\sum_{i=1}^{n}\left(y_{i}-\hat{y}_{i}\right)^{2}}{\sum_{i=1}^{n}\left(y_{i}-\bar{y}_{i}\right)^{2}}
$$

where $\bar{y}$ is the mean of dependent variables (experimentally observed) and $\hat{y}$ is the predicted value from the model. The selected network is the one with the highest $R^{2}$ and lowest MSE for all training, test, and validation data. The difference between the actual value of output and the predicted value for each data set is recorded as an error. Different network architectures were assumed by increasing the number of neurons in the hidden layer, and the one with the lowest MSE was selected as the best model to be used.

From the selected networks, it was possible to determine the relative effect of the input variables on the value of output. This was done by calculating the "contribution" of $i$ th input data to $k$ th output data $\left(C_{i k}\right)$ for every input variable according to Equation $3 .{ }^{38}$

$$
C_{i k}=\left|\sum_{j} a_{i j} \times b_{j k}\right|
$$

\section{Results and discussion}

Di- and triblock copolymers were efficiently prepared by ring-opening polymerization in different molecular weights of PLA blocks using mPEG $1.9 \mathrm{kDa}$ and PEG $2.0 \mathrm{kDa}$ as starting materials. The ${ }^{1} \mathrm{H}$ NMR analyses of the prepared polymers showed the characteristic peaks of PLA at $5.15 \mathrm{ppm}$ (methine $[\mathrm{CH}]$ proton, tetralet split; Figure $3 \mathrm{~A}$ ) and at 1.60 (methyl $\left[\mathrm{CH}_{3}\right]$ protons, doublet split; Figure $3 \mathrm{~B}$ ) and the characteristic peak of PEG at $3.65 \mathrm{ppm}$ (methylene $\left[\mathrm{CH}_{2}\right]$ protons, triplet split; Figure 3C). The molecular weights of copolymers were calculated by integration of ${ }^{1} \mathrm{H}$ NMR and GPC (Table 1).

Zeta potential was in the range of $-1.96 \mathrm{mV}$ to $-30.20 \mathrm{mV}$ and particle sizes were in the range of $42.75 \mathrm{~nm}$ to $485.57 \mathrm{~nm}$. Entrapment efficiency of noscapine was determined and found to be in the range of $2.79 \%$ to $41.89 \%$, as shown in Table 3 . The morphology of the prepared NPs was analyzed 


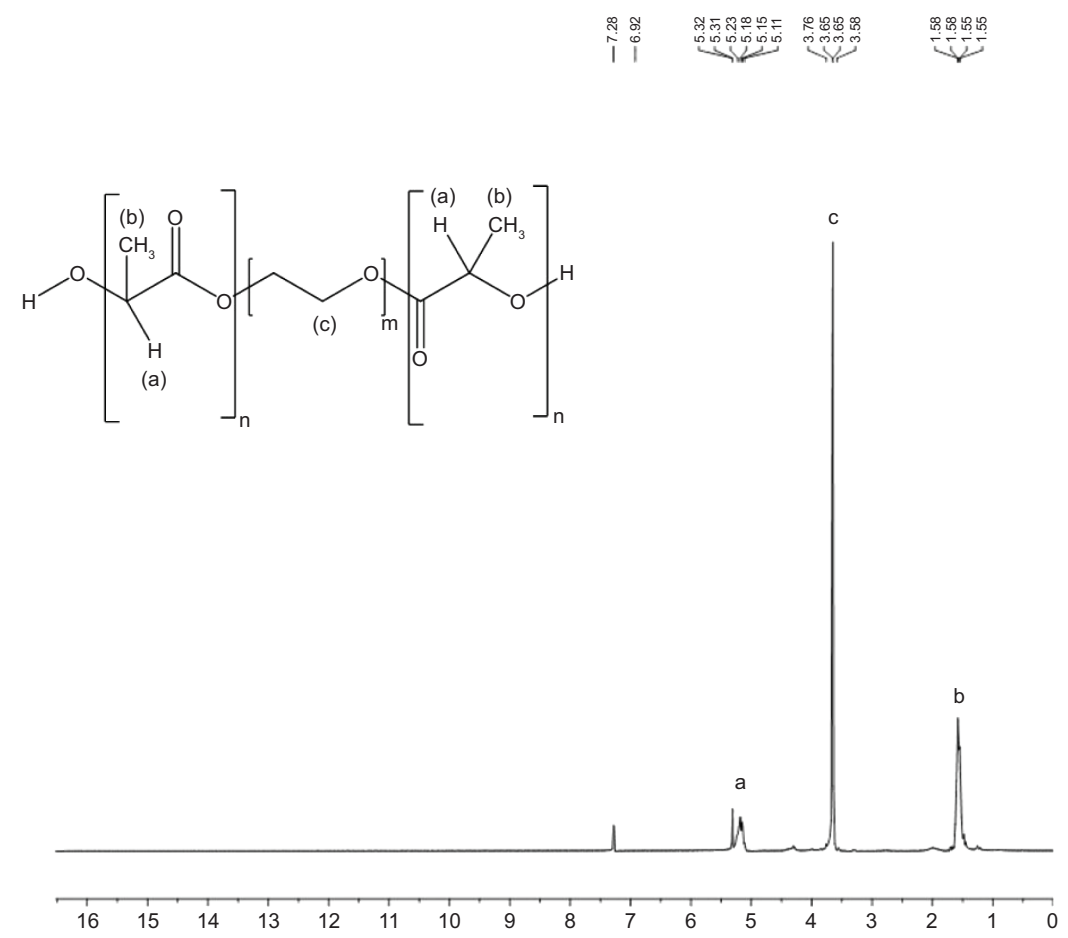

Figure $3200 \mathrm{MHz}$ proton nuclear magnetic resonance spectrum of polylactide-polyethylene glycol-polylactide triblock copolymer (P2) in CDCl.

Table 3 Size, polydispersity index (PDI), zeta potential, and noscapine entrapment efficiency of prepared nanoparticles

\begin{tabular}{llllll}
\hline Polymer & Ratio & $\begin{array}{l}\text { Size } \\
\text { (nm) }\end{array}$ & PDI & $\begin{array}{l}\text { Zeta } \\
\text { potential }\end{array}$ & $\begin{array}{l}\text { Entrapment } \\
\text { efficiency }\end{array}$ \\
\hline PI & $20: 1$ & 110.80 & 0.496 & -19.64 & 32.11 \\
& $10: 1$ & 278.40 & 0.504 & -12.90 & 5.77 \\
& $5: 1$ & 201.00 & 0.352 & -20.53 & 6.13 \\
& $2.5: 1$ & 271.90 & 0.362 & -17.70 & 8.74 \\
P2 & $20: 1$ & 87.49 & 0.368 & -1.96 & 27.41 \\
& $10: 1$ & 137.97 & 0.352 & -11.08 & 7.85 \\
& $5: 1$ & 180.37 & 0.348 & -26.73 & 17.59 \\
& $2.5: 1$ & 124.95 & 0.42 & -27.20 & 28.15 \\
P3 & $10: 1$ & 91.63 & 0.354 & -18.07 & 22.15 \\
& $5: 1$ & 82.72 & 0.234 & -9.96 & 17.62 \\
& $2.5: 1$ & 71.59 & 0.380 & -30.20 & 24.09 \\
P4 & $20: 1$ & 129.35 & 0.44 & -9.36 & 24.78 \\
& $10: 1$ & 130.93 & 0.326 & -24.13 & 36.65 \\
& $5: 1$ & 148.13 & 0.288 & -27.20 & 30.16 \\
& $2.5: 1$ & 166.90 & 0.344 & -28.50 & 23.36 \\
P5 & $20: 1$ & 63.32 & 0.598 & -8.81 & 32.04 \\
& $10: 1$ & 121.90 & 0.36 & -18.80 & 21.94 \\
& $5: 1$ & 128.30 & 0.31 & -23.05 & 26.01 \\
& $2.5: 1$ & 217.40 & 0.394 & -18.37 & 35.82 \\
P6 & $20: 1$ & 485.57 & 0.83 & -2.57 & 41.89 \\
& $10: 1$ & 228.90 & 0.38 & -17.35 & 25.95 \\
& $5: 1$ & 115.20 & 0.34 & -21.80 & 19.29 \\
& $2.5: 1$ & 97.84 & 0.59 & -22.30 & 2.79 \\
& $20: 1$ & 43.950 & 0.489 & -7.900 & 36.90 \\
& $10: 1$ & 42.75 & 0.405 & -10.54 & 38.58 \\
& $5: 1$ & 153.63 & 0.383 & -19.07 & 13.10 \\
& $2.5: 1$ & 200.63 & 0.448 & -9.97 & 36.42 \\
\hline & & & & &
\end{tabular}

with TEM, which showed the ability of PEG/PLA copolymers to form small size NPs (Figure 4).

The experimental factors that were previously tested and known to affect the particle size of the prepared NPs, namely stirring rate, drug concentration, and solvent ratio, were kept constant during the determination of the effect of the three input variables (polymer molecular weight, number of blocks in the copolymer used, and ratio of polymer to drug) tested in this paper on the particle size of the formed NPs, with the exception of polymer to drug ratios, which were selected to fit the present study of our polymers and noscapine. ${ }^{31}$

\section{Data analysis using ANNs to determine the variables that affect the particle size}

A neural network composed of three-layered feed-forward back-propagation $(3: 10: 1)$ was used to model the effect of the input variables (polymer molecular weight, number of blocks per polymer, and ratio of polymer to drug) on the particle size of the formed NPs. Twenty-one individual data sets were randomly selected as "training data", while two sets, each composed of three individual data sets, were randomly selected as "validation data" and "test data" (Table 4). The best predictive model gave $R^{2}$ and MSE values of 0.97838 and $372.3,0.96047$ and 54.26, and 0.95368 


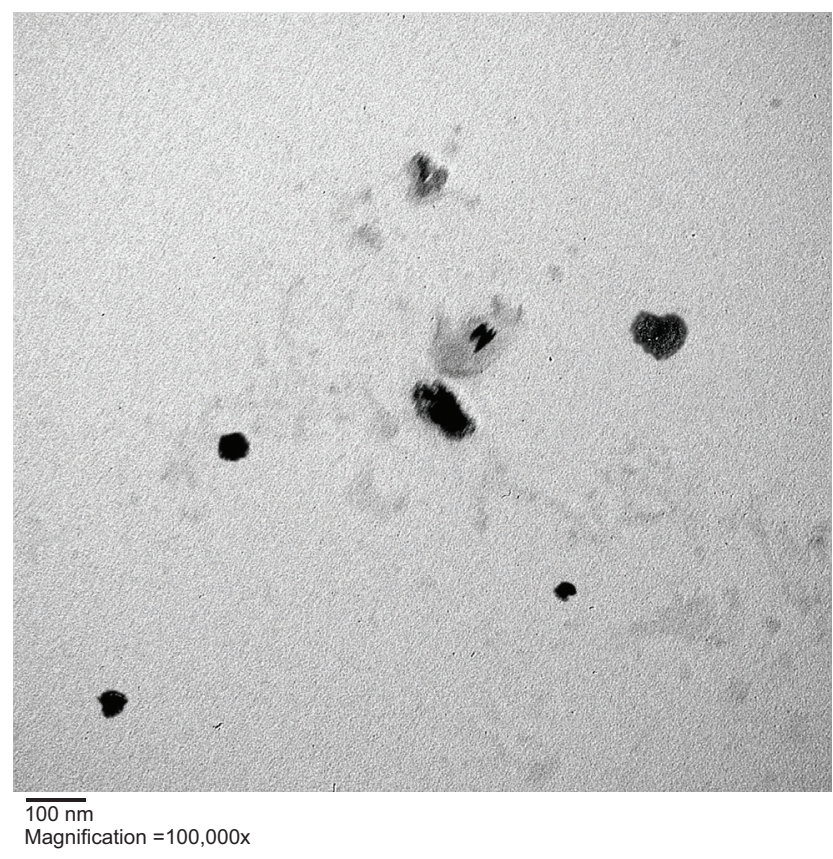

Figure 4 Transmission electron microscopy image of nanoparticles formed from polylactide and polyethylene glycol copolymer (P3). and 478 for training, validation, and test data, respectively. The overall $R^{2}$ for the model was 0.97833 , indicating the quality of the trained network and its predictive capabilities (Figure 5).

Determination of $C_{i k}$ using Equation 3 indicated that the effect of variables on particle size was in the order of polymer molecular weight $>$ polymer to drug ratio $>$ number of blocks in copolymer (Table 5). The $C_{i k}$ results were supported by 3-D surface plots of the predicted particle sizes from the model for di- and triblock copolymers, as shown in Figure 6A and $\mathrm{B}$, respectively. These plots showed an increase in NP sizes as the polymer molecular weight increased, as previously reported by Riley et al. ${ }^{39}$

\section{Determination of variables that affect noscapine entrapment efficiency}

Another neural network composed of three-layered feedforward back-propagation (3:7:1) was used to model the effect of the input variables (polymer molecular weight,

Table 4 The observed and predicted particle size in "training", "validation", and "test" data

\begin{tabular}{|c|c|c|c|}
\hline Sample number & $\begin{array}{l}\text { Observed particle } \\
\text { size }(\mathrm{nm})\end{array}$ & $\begin{array}{l}\text { Predicted particle } \\
\text { size }(\mathrm{nm})\end{array}$ & $\begin{array}{l}\text { Particle size error } \\
(\mathrm{nm})\end{array}$ \\
\hline $\mathrm{I}$ & 129.35 & 139.21 & -9.86 \\
\hline 2 & 130.93 & 124.83 & 6.10 \\
\hline 3 & 148.13 & 155.26 & -7.13 \\
\hline 4 & 166.90 & 202.53 & -35.63 \\
\hline 5 & 110.80 & 79.49 & 31.31 \\
\hline 6 & 278.40 & 268.62 & 9.78 \\
\hline 7 & 201.00 & 233.45 & -32.45 \\
\hline 8 & 271.90 & 252.27 & 19.63 \\
\hline $9^{a}$ & 63.32 & 53.22 & 10.10 \\
\hline $10^{\mathrm{b}}$ & 121.90 & 91.10 & 30.80 \\
\hline II & 128.30 & 159.40 & -31.10 \\
\hline $12^{\mathrm{b}}$ & 217.40 & 236.32 & -18.92 \\
\hline $13^{\mathrm{a}}$ & 87.49 & 79.99 & 7.50 \\
\hline 14 & 137.97 & 139.18 & -1.21 \\
\hline 15 & 180.37 & 140.58 & 39.79 \\
\hline 16 & 124.95 & 119.31 & 5.64 \\
\hline 17 & 485.57 & 465.42 & 20.15 \\
\hline 18 & 228.90 & 224.56 & 4.34 \\
\hline 19 & 115.20 & 119.76 & -4.56 \\
\hline $20^{\mathrm{b}}$ & 97.84 & 109.13 & -11.29 \\
\hline 21 & 91.63 & 96.19 & -4.56 \\
\hline 22 & 82.72 & 76.59 & 6.13 \\
\hline 23 & 71.59 & 66.55 & 5.04 \\
\hline $24^{\mathrm{a}}$ & 46.29 & $48.4 I$ & -2.12 \\
\hline 25 & 42.75 & 51.51 & -8.76 \\
\hline 26 & 153.63 & 129.27 & 24.36 \\
\hline 27 & 200.63 & 208.69 & -8.06 \\
\hline
\end{tabular}

Notes: ${ }^{\mathrm{a}}$ and ${ }^{\mathrm{b}}$ indicate the input data sets used as the "validation data" and "test data", respectively. 
Training: $R^{2}=0.97838$

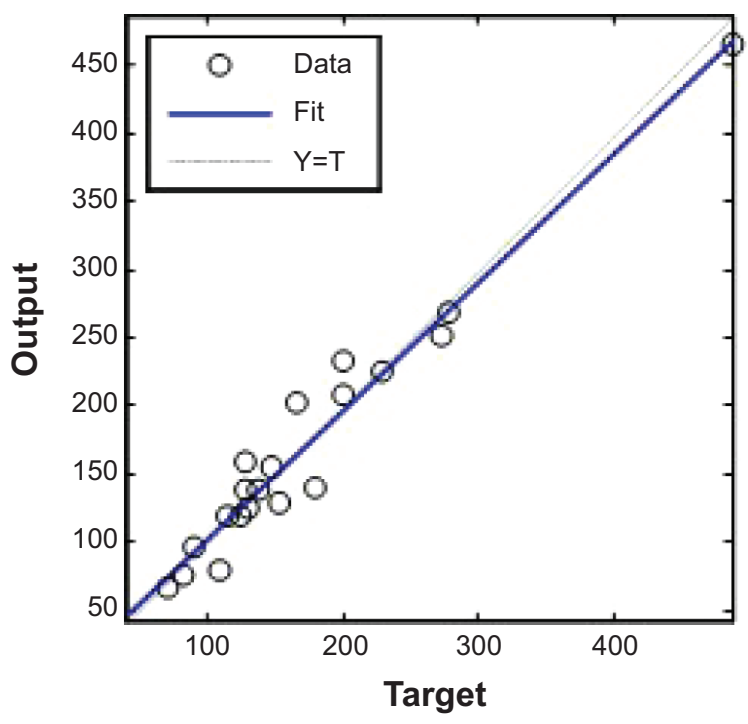

Test: $R^{2}=0.95368$

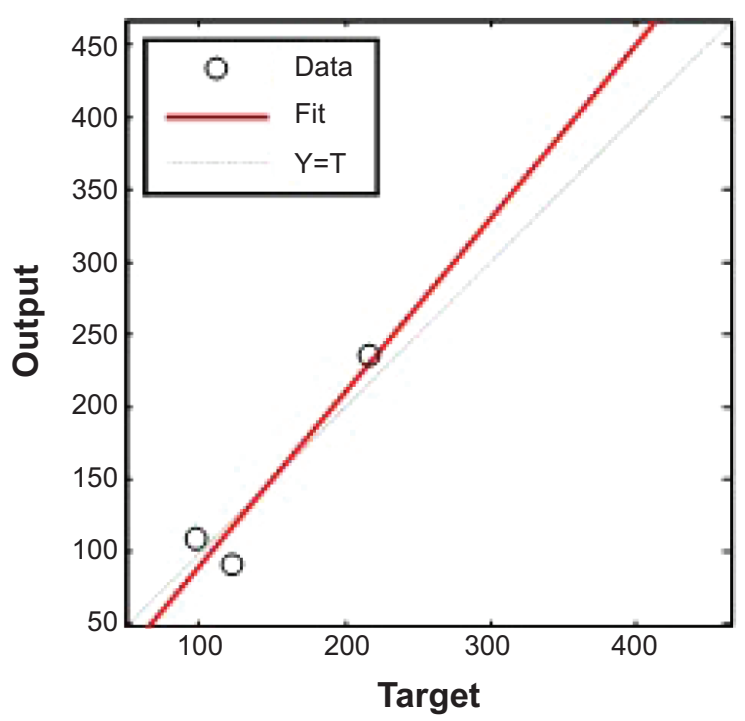

Validation: $R^{2}=0.96047$

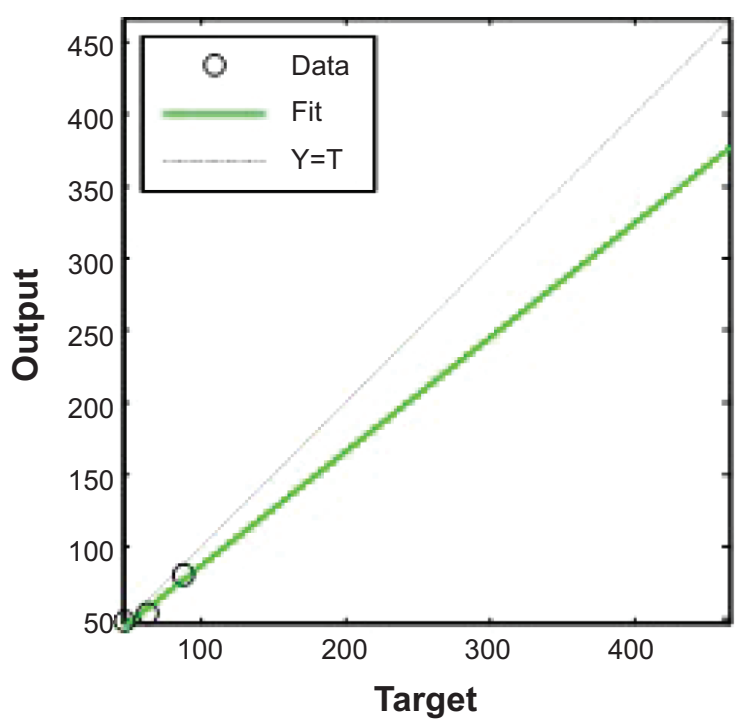

All: $R^{2}=0.97833$

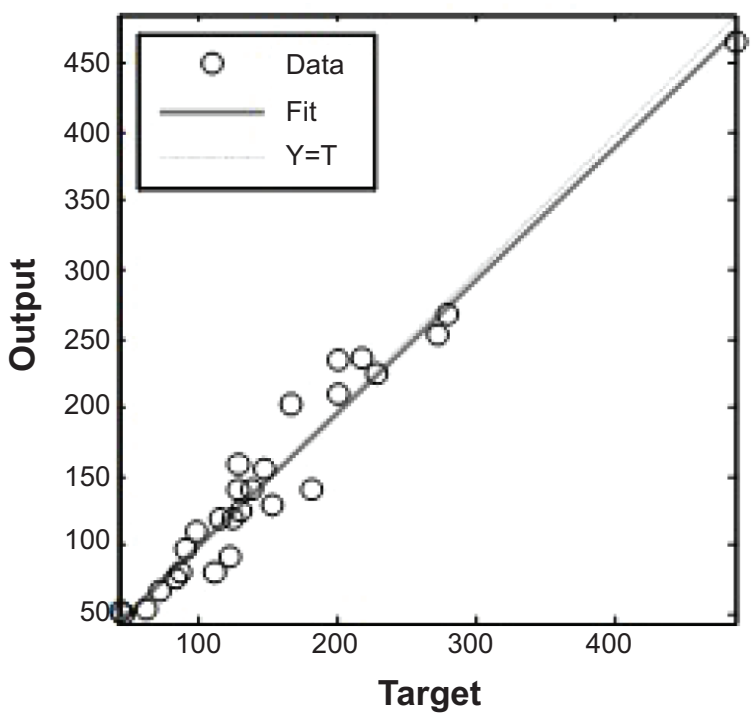

Figure 5 Actual versus predicted size from network and regression for training, validation, test, and all data sets.

number of blocks per polymer, and ratio of polymer to drug) on noscapine entrapment efficiency in the NPs formed. Nineteen individual data sets were randomly selected as "training data", while two sets, each composed of four individual data sets, were randomly selected as "validation data" and "test data" (Table 6). This model showed $R^{2}$ and MSE values of

Table 5 Relative contribution of input variables in particle size

\begin{tabular}{ll}
\hline Factor & $\boldsymbol{C}_{i k}$ \\
\hline Polymer molecular weight & 6.385 \\
Polymer:drug ratio & 4.867 \\
Number of blocks in polymer & 0.147 \\
\hline
\end{tabular}

0.97414 and 5.951, 0.97022 and 14.49, and 0.91486 and 13.95 for training, validation, and test data, respectively. The overall $R^{2}$ for the model was 0.96484 , which indicates its high predictability (Figure 7).

Since the same drug formulae used for particle size modeling were used to measure entrapment efficiency, the inputs in these models were the same for the model used for particle size prediction, but the output in this model was set to be noscapine entrapment efficiency. $C_{i k}$ values were determined for all input variables, and it was found that the polymer to drug ratio was the most influential factor, as it has the highest $C_{i k}$, followed by the number of 

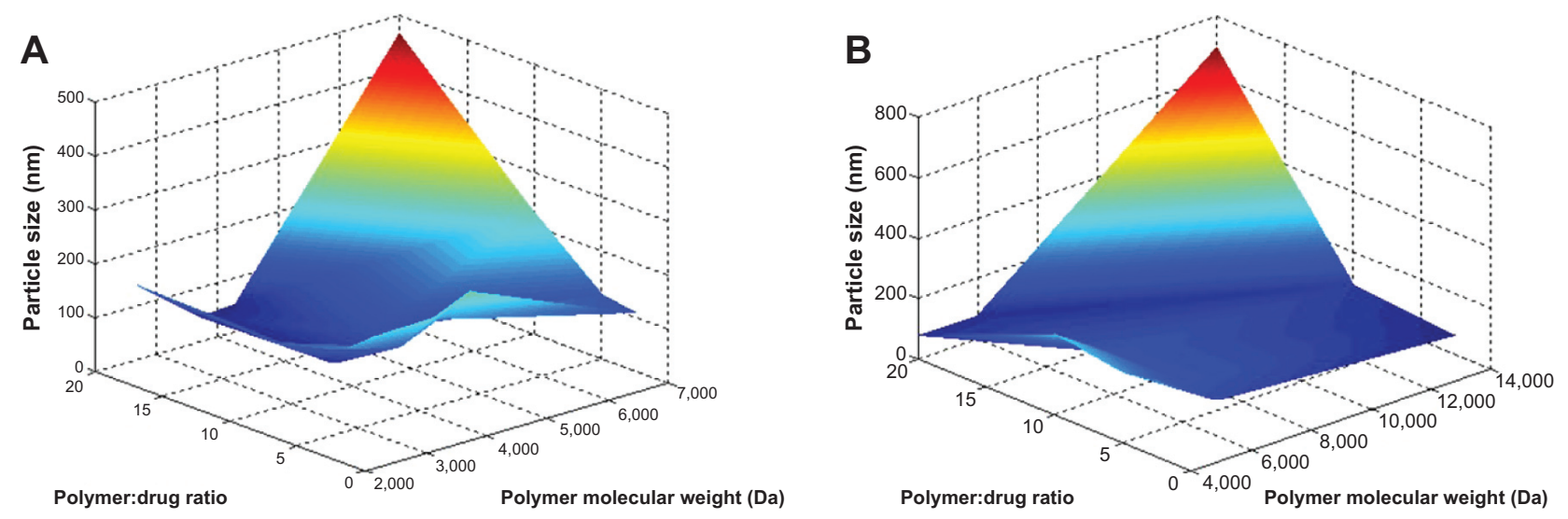

Figure 6 Three-dimensional surface plots of predicted particle sizes at different polymer molecular weights and polymer:drug ratios.

Note: (A) Diblock copolymer and (B) triblock copolymer.

blocks in copolymer and then polymer molecular weight, as shown in Table 7. The 3-D surface plots of predicted entrapment efficiency from the model after dividing them into di- and triblock copolymers also showed a strong effect of the polymer to drug ratio on drug entrapment efficiency (Figure 8A and B). These results coincide with previously reported experiments on PLA and PEG copolymers in which it was observed that polymer to drug ratio was the most influential factor on drug entrapment efficiency. ${ }^{40}$ When the drug was water soluble, the drug entrapment efficiency decreased as that ratio increased, perhaps due to the rapid distribution of drug into water during nanoprecipitation

Table 6 The observed and predicted drug entrapment efficiency in "training", "validation", and "test" data

\begin{tabular}{|c|c|c|c|}
\hline Sample number & $\begin{array}{l}\text { Observed drug entrapment } \\
\text { efficiency (\%) }\end{array}$ & $\begin{array}{l}\text { Predicted drug entrapment } \\
\text { efficiency (\%) }\end{array}$ & $\begin{array}{l}\text { Drug entrapment efficiency } \\
\text { error (\%) }\end{array}$ \\
\hline $\mathrm{I}$ & 24.78 & 24.55 & 0.22 \\
\hline 2 & 36.65 & 35.10 & 1.55 \\
\hline 3 & 30.16 & 29.32 & 0.85 \\
\hline 4 & 23.36 & 28.91 & -5.55 \\
\hline 5 & 32.11 & 30.66 & 1.45 \\
\hline 6 & 5.77 & 5.13 & 0.63 \\
\hline $7^{a}$ & 6.13 & 6.67 & -0.54 \\
\hline $8^{a}$ & 8.74 & 9.75 & -1.01 \\
\hline 9 & 32.04 & 32.12 & -0.08 \\
\hline $10^{\mathrm{b}}$ & 21.94 & 28.95 & -7.01 \\
\hline $1 \mathrm{I}^{\mathrm{a}}$ & 26.01 & 18.48 & 7.53 \\
\hline 12 & 35.82 & 37.77 & -1.95 \\
\hline $13^{b}$ & $27.4 I$ & 29.33 & -1.92 \\
\hline 14 & 7.85 & 7.96 & -0.12 \\
\hline 15 & 17.59 & 17.70 & -0.11 \\
\hline $16^{\mathrm{b}}$ & 28.15 & 29.41 & -1.26 \\
\hline $17^{a}$ & 41.89 & 41.88 & 0.01 \\
\hline 18 & 25.95 & 26.64 & -0.69 \\
\hline 19 & 19.29 & $|8.5|$ & 0.77 \\
\hline 20 & 2.79 & 2.79 & -0.01 \\
\hline 21 & 22.15 & 22.19 & -0.04 \\
\hline 22 & 17.62 & 17.52 & 0.10 \\
\hline 23 & 24.09 & 24.13 & -0.03 \\
\hline 24 & 36.90 & 36.94 & -0.04 \\
\hline 25 & 38.58 & 37.00 & 1.58 \\
\hline 26 & 13.10 & 21.42 & -8.32 \\
\hline $27^{b}$ & 36.42 & 35.23 & 1.19 \\
\hline
\end{tabular}

Note: ${ }^{a}$ and ${ }^{b}$ indicate the input data sets used as the "validation data" and "test data", respectively. 
Training: $R^{2}=0.97414$

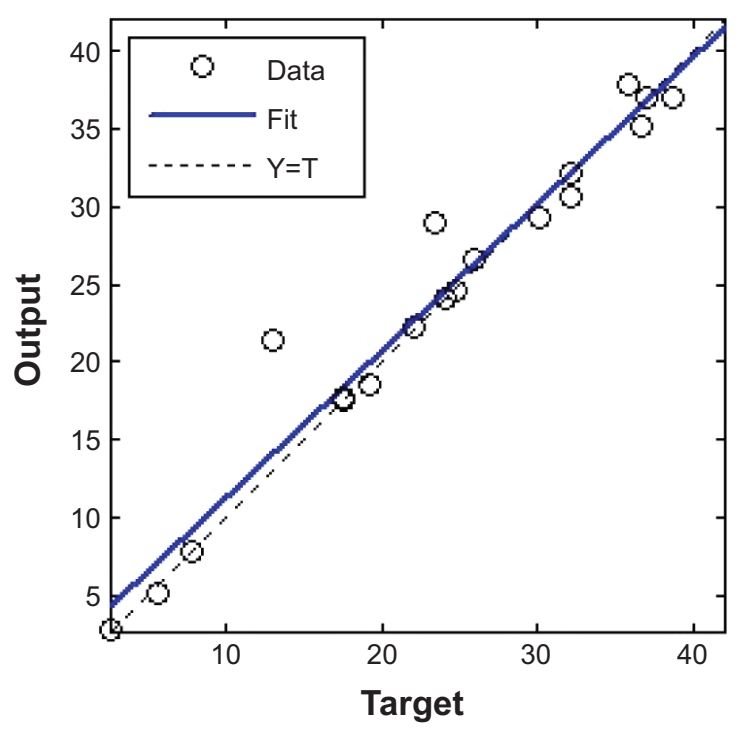

Test: $R^{2}=0.91486$

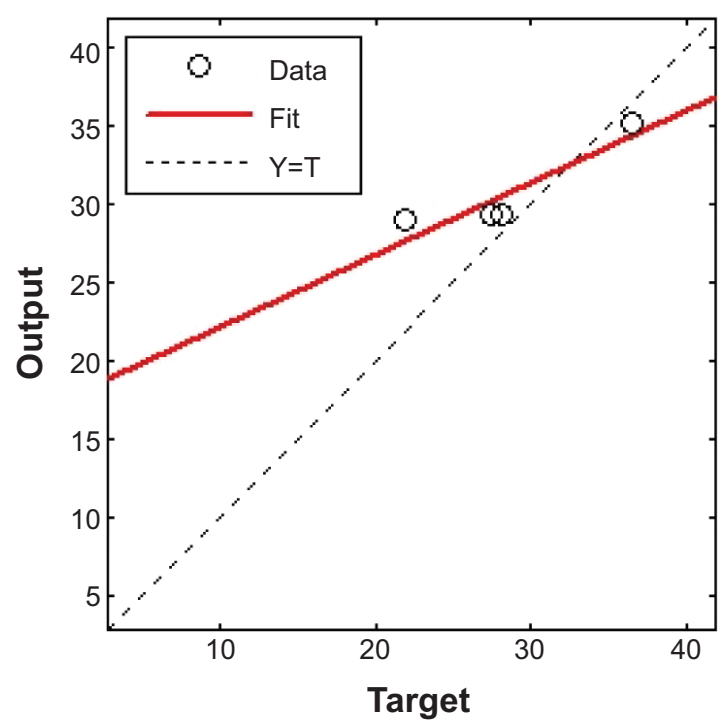

Validation: $R^{2}=0.97022$

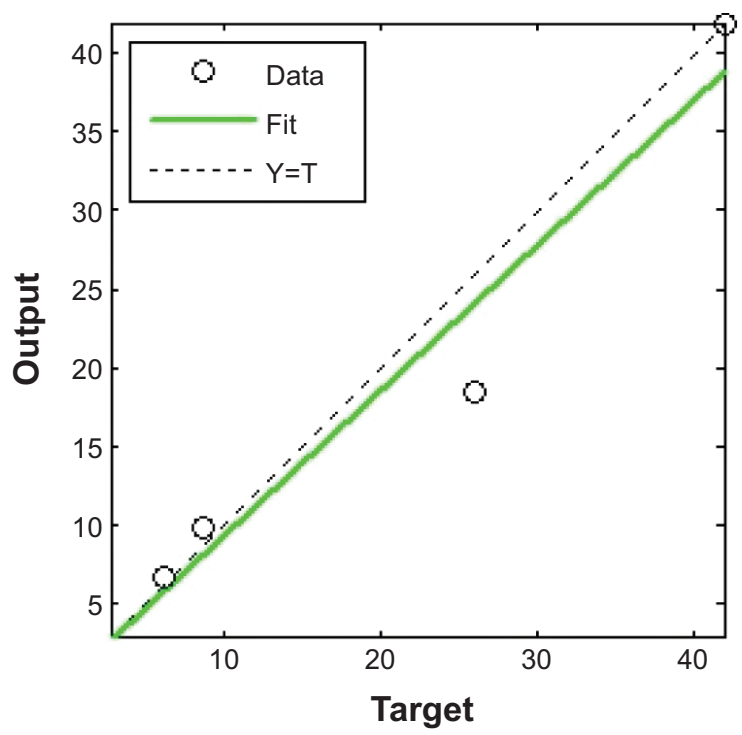

All: $R^{2}=0.96484$

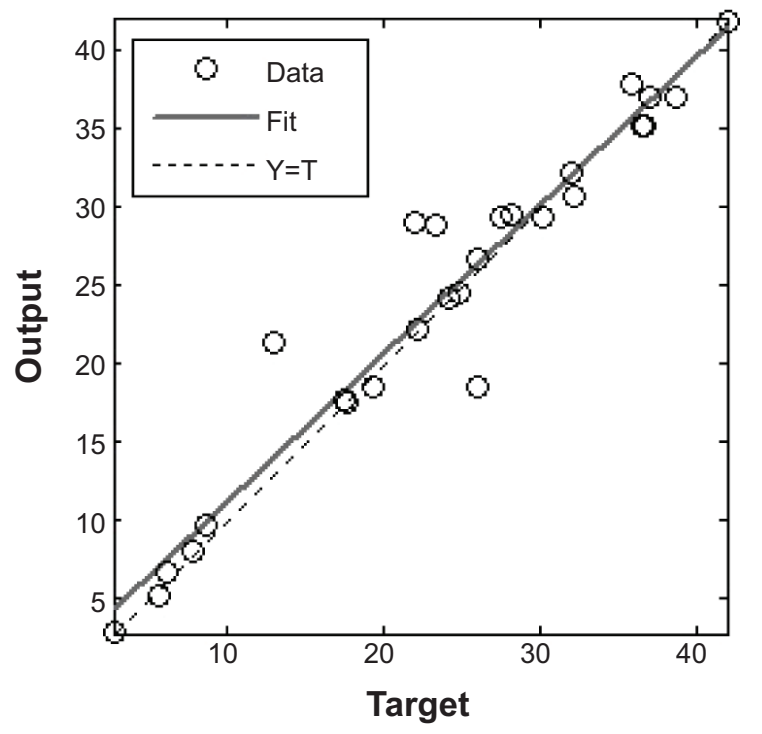

Figure 7 Actual versus predicted drug entrapment efficiency from network and regression for training, validation, test, and all data sets.

with the aggregation of polymer molecules. Instead, in the case of insoluble drugs such as moscapine, the drug will be incorporated into polymeric NPs, causing an increase in entrapment efficiency as the ratio of polymer to drug increases..$^{39,40}$

Table 7 Relative contribution of input variables in noscapine entrapment efficiency

\begin{tabular}{ll}
\hline Factor & $\boldsymbol{C}_{i k}$ \\
\hline Polymer molecular weight & 2.703 \\
Polymer:drug ratio & 38.964 \\
Number of blocks in polymer & 10.300 \\
\hline
\end{tabular}

\section{Conclusion}

Di- and triblock copolymers of PEG and PLA were synthesized and detected by ${ }^{1} \mathrm{H}$ NMR and GPC. The formed copolymers were used in the preparation of NPs by nanoprecipitation technique. The prepared NPs were characterized by the determination of drug entrapment efficiency and measuring their particle size using dynamic light scattering. Morphological studies were also done using TEM imaging to confirm sizes ascertained by light scattering. In this study, we succeeded in constructing two networks of different architectures that had the ability to predict the particle size and noscapine entrapment efficiency within the formed noscapine-loaded 

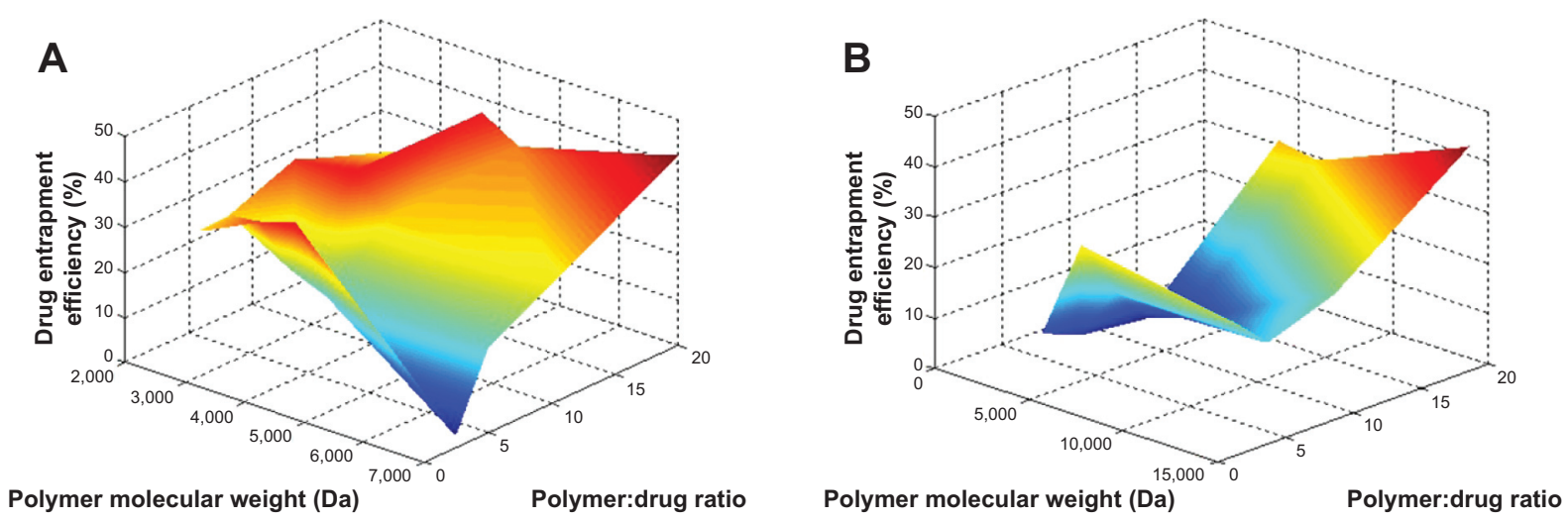

Figure 8 Three-dimensional surface plots of predicted drug entrapment efficiency at different polymer molecular weights and polymer:drug ratios. Note: (A) Diblock copolymer and (B) triblock copolymer.

polymeric NPs, utilizing the input variables of molecular weight of polymer, ratio of polymer to drug, and number of blocks from which the polymer was composed. It was also possible to determine the relative effect of the different input variables on the output.

It was found that polymer molecular weight had the greatest effect on particle size, while polymer to drug ratio was the most influential factor on noscapine entrapment efficiency. Data generated from the ANN model in the form of 3-D graphs were used to determine the importance of the input variables. They showed that there were strong interactions between input variables and the output. These trained ANNs served to predict the particle size and drug entrapment efficiency in noscapineloaded NPs formed using the tested block copolymers.

\section{Disclosure}

The authors report no conflicts of interest in this work.

\section{References}

1. Gong J, Chen M, Zheng Y, Wang S, Wang Y. Polymeric micelles drug delivery system in oncology. J Control Release. 2012;159(3):312-323.

2. Nishiyama N, Kataoka K. Current state, achievements, and future prospects of polymeric micelles as nanocarriers for drug and gene delivery. Pharmacol Ther. 2006;112(3):630-648.

3. Shin HC, Alani AW, Rao DA, Rockich NC, Kwon GS. Multi-drug loaded polymeric micelles for simultaneous delivery of poorly soluble anticancer drugs. J Control Release. 2009;140(3):294-300.

4. Venkatraman SS, Jie P, Min F, Freddy BY, Leong-Huat G. Micelle-like nanoparticles of PLA-PEG-PLA triblock copolymer as chemotherapeutic carrier. Int J Pharm. 2005;298(1):219-232.

5. Dahlstrom B, Mellstrand T, Lofdahl CG, Johansson M. Pharmacokinetic properties of noscapine. Eur J Clin Pharmacol. 1982;22(6):535-539.

6. Segal MS, Goldstein MM, Attinger EO. The use of noscapine (narcotine) as an antitussive agent. Dis Chest. 1957;32(3):305-309.

7. Heidemann S. Microtubules, leukemia, and cough syrup. Blood. 2006; 107(6):2216-2217.

8. Yang Z-R, Liu M, Peng X-L, Lei X-F, Zhang J-X, Dong W-G. Noscapine induces mitochondria-mediated apoptosis in human colon cancer cells in vivo and in vitro. Biochem Biophys Res Commun. 2012;421(3):627-633.

9. Aneja R, Lopus M, Zhou J, et al. Rational design of the microtubule-targeting anti-breast cancer drug EM015. Cancer Res. 2006;66(7):3782-3791.
10. Aneja R, Zhou J, Vangapandu SN, Zhou B, Chandra R, Joshi HC. Drugresistant T-lymphoid tumors undergo apoptosis selectively in response to an antimicrotubule agent, EM011. Blood. 2006;107(6):2486-2492.

11. Ye K, Zhou J, Landen JW, Bradbury EM, Joshi HC. Sustained activation of p34 cdc2 is required for noscapine-induced apoptosis. J Biol Chem. 2001;276(50):46697-46700.

12. Aneja R, Ghaleb AM, Zhou J, Yang VW, Joshi HC. p53 and p21 determine the sensitivity of noscapine-induced apoptosis in colon cancer cells. Cancer Res. 2007;67(8):3862-3870.

13. Zhou J, Gupta K, Yao J, et al. Paclitaxel-resistant human ovarian cancer cells undergo c-Jun NH2-terminal kinase-mediated apoptosis in response to noscapine. J Biol Chem. 2002;277(42):39777-39785.

14. Zhou J, Panda D, Landen JW, Wilson L, Joshi HC. Minor alteration of microtubule dynamics causes loss of tension across kinetochore pairs and activates the spindle checkpoint. J Biol Chem. 2002;277(19):17200-17208.

15. Ye K, Ke Y, Keshava N, et al. Opium alkaloid noscapine is an antitumor agent that arrests metaphase and induces apoptosis in dividing cells. Proc Natl Acad Sci U S A. 1998;95(4):1601-1606.

16. Landen JW, Lang R, McMahon SJ, et al. Noscapine alters microtubule dynamics in living cells and inhibits the progression of melanoma. Cancer Res. 2002;62(14):4109-4114.

17. Aneja R, Dhiman N, Idnani J, et al. Preclinical pharmacokinetics and bioavailability of noscapine, a tubulin-binding anticancer agent. Cancer Chemother Pharmacol. 2007;60(6):831-839.

18. Chougule MB, Patel A, Sachdeva P, Jackson T, Singh M. Enhanced anticancer activity of gemcitabine in combination with noscapine via antiangiogenic and apoptotic pathway against non-small cell lung cancer. PLoS One. 2011;6(11):e27394.

19. Abdalla MO, Karna P, Sajja HK, et al. Enhanced noscapine delivery using uPAR-targeted optical-MR imaging trackable nanoparticles for prostate cancer therapy. J Control Release. 2011;149(3): 314-322.

20. Jackson T, Chougule MB, Ichite N, Patlolla RR, Singh M. Antitumor activity of noscapine in human non-small cell lung cancer xenograft model. Cancer Chemother Pharmacol. 2008;63(1):117-126.

21. Landen JW, Hau V, Wang M, et al. Noscapine crosses the blood-brain barrier and inhibits glioblastoma growth. Clin Cancer Res. 2004; 10(15):5187-5201.

22. Agatonovic-Kustrin S, Beresford R. Basic concepts of artificial neural network (ANN) modeling and its application in pharmaceutical research. J Pharm Biomed Anal. 2000;22(5):717-727.

23. Hussain AS, Shivanand P, Johnson RD. Application of neural computing in pharmaceutical product development: computer aided formulation design. Drug Dev Ind Pharm. 1994;20(10):1739-1752.

24. Sutariya VB, Groshev A, Pathak YV. Artificial neural networks in pharmaceutical research, drug delivery and pharmacy curriculum. Paper presented at: Biomedical Engineering Conference (SBEC), 2013 29th Southern; May 3-5, 2013. 
25. Agatonovic-Kustrin S, Tucker IG, Schmierer D. Solid state assay of ranitidine $\mathrm{HCl}$ as a bulk drug and as active ingredient in tablets using DRIFT spectroscopy with artificial neural networks. Pharm Res. 1999; 16(9):1477-1482.

26. Ma J, Cai J, Lin G, Chen H, Wang X, Hu L. Development of LC-MS determination method and back-propagation ANN pharmacokinetic model of corynoxeine in rat. J Chromatogr B Analyt Technol Biomed Life Sci. 2014;959C:10-15.

27. Agatonovic-Kustrin S, Wu V, Rades T, Saville D, Tucker IG. Ranitidine hydrochloride X-ray assay using a neural network. J Pharm Biomed Anal. 2000;22(6):985-992.

28. Ebube NK, Owusu-Ababio G, Adeyeye CM. Preformulation studies and characterization of the physicochemical properties of amorphous polymers using artificial neural networks. Int J Pharm. 2000; 196(1):27-35

29. Sathe PM, Venitz J. Comparison of neural network and multiple linear regression as dissolution predictors. Drug Dev Ind Pharm. 2003; 29(3):349-355.

30. Amani A, York P, Chrystyn H, Clark BJ, Do DQ. Determination of factors controlling the particle size in nanoemulsions using artificial neural networks. Eur J Pharm Sci. 2008;35(1-2):42-51.

31. Asadi H, Rostamizadeh K, Salari D, Hamidi M. Preparation of biodegradable nanoparticles of tri-block PLA-PEG-PLA copolymer and determination of factors controlling the particle size using artificial neural network. J Microencapsul. 2011;28(5):406-416.

32. Husseini GA, Mjalli FS, Pitt WG, Abdel-Jabbar N. Using artificial neural networks and model predictive control to optimize acoustically assisted doxorubicin release from polymeric micelles. Technol Cancer Res Treat. 2009;8(6):479-488.
33. Perinelli DR, Bonacucina G, Cespi M, et al. Evaluation of P(L)LA-PEG$\mathrm{P}(\mathrm{L}) \mathrm{LA}$ as processing aid for biodegradable particles from gas saturated solutions (PGSS) process. Int J Pharm. 2014;468(1-2):250-257.

34. Cespi M, Casettari L, Bonacucina G, Giorgioni G, Perinelli DR, Palmieri GF. Evaluation of methoxy polyethylene glycol-polylactide diblock copolymers as additive in hypromellose film coating. Polym Adv Technol. 2013;24(11):1018-1024.

35. Kaihara S, Matsumura S, Mikos AG, Fisher JP. Synthesis of poly(Llactide) and polyglycolide by ring-opening polymerization. Nat Protocols. 2007;2(11):2767-2771.

36. Fessi H, Puisieux F, Devissaguet JP, Ammoury N, Benita S. Nanocapsule formation by interfacial polymer deposition following solvent displacement. Int J Pharm. 1989;55(1):R1-R4.

37. Rizkalla N, Hildgen P. Artificial neural networks: comparison of two programs for modeling a process of nanoparticle preparation. Drug Dev Ind Pharm. 2005;31(10):1019-1033.

38. Hattori T, Kito S. Analysis of factors controlling catalytic activity by neural network. Catalysis Today. 2006;111(3-4):328-332.

39. Riley T, Govender T, Stolnik S, et al. Colloidal stability and drug incorporation aspects of micellar-like PLA-PEG nanoparticles. Colloids Surf B Biointerfaces. 1999;16(1-4):147-159.

40. Leo E, Brina B, Forni F, Vandelli MA. In vitro evaluation of PLA nanoparticles containing a lipophilic drug in water-soluble or insoluble form. Int J Pharm. 2004;278(1):133-141
International Journal of Nanomedicine

\section{Publish your work in this journal}

The International Journal of Nanomedicine is an international, peerreviewed journal focusing on the application of nanotechnology in diagnostics, therapeutics, and drug delivery systems throughout the biomedical field. This journal is indexed on PubMed Central, MedLine, CAS, SciSearch ${ }^{\circledR}$, Current Contents ${ }^{\circledR} /$ Clinical Medicine,

\section{Dovepress}

Journal Citation Reports/Science Edition, EMBase, Scopus and the Elsevier Bibliographic databases. The manuscript management system is completely online and includes a very quick and fair peer-review system, which is all easy to use. Visit http://www.dovepress.com/ testimonials.php to read real quotes from published authors. 